\title{
Research on the Teaching Pattern of Cultivating College Students' Innovative and Practical Ability Based on Subject Competition
}

\author{
Wang Bangfu \\ The Suzhou University of Science and Technology \\ Suzhou, China
}

\author{
Zhu Qixin \\ The Suzhou University of Science and Technology \\ Suzhou, China
}

\author{
Wang Jun \\ China University of Mining and Technology \\ Xuzhou, China
}

\begin{abstract}
In order to strengthen students' practical ability and cultivate their innovation consciousness, subject competition system is established using subject competition as carrier. The paper analyzes and explores the operation mechanism of subject competition system on cultivating college students' innovative and practical ability, and proposes strategies and approaches to promote the cultivation of college students' innovative and practical ability through subject competition, which is of great significance to the improvement of college students' practical teaching quality.
\end{abstract}

Keywords-Subject Competition; Innovative and Practical Ability; Comprehensive Ability

\section{INTRODUCTION}

Cultivating students' practical and innovative ability is not only one of the main tasks of higher education in China, but also an important content in the training of new horizon talents. Subject competition aims to improve the students' innovative and practical ability, and focuses on innovative education. It has become an effective means to improve college students' comprehensive quality. The subject competition stimulates students' innovation consciousness, promotes the construction of teaching and learning style, and guides colleges and universities to pay attention to cultivating students' innovative thinking, scientific research ability and practical ability in educational reform. It strengthens team spirit, and creates a strong science and technology culture atmosphere in campus. It has an important role in promoting the improvement of college students' comprehensive quality and many other aspects.

Strengthen the quality of practical teaching and stimulate students' initiative and innovation awareness through the competition. During the preparation of the competition, students take the initiative to learn the relevant knowledge, conduct positive thinking, actively participate in training and form good learning habits of self-learning. It significantly improves the learning and teaching effect, not only enhancing engineering ability, but also consolidating and sublimating the professional knowledge in the training. Meanwhile, competition also helps students develop team spirit, safety awareness, environmental awareness and cost-saving awareness, further enhancing the students' operating skills and comprehensive quality. It is of great significance to conduct educational reform and practice based on cultivation of innovative and practical ability and form personnel training mode with practical teaching characteristics.

\section{SubJeCt COMPETITION System ARChiteCture}

\section{A. Establish Innovative Credit System and Encourage the Development of Subject Competition}

Introduce innovative credit system into the talent cultivation program of school of mechanical engineering, Suzhou University of Science and Technology, and clearly stipulate that the second classroom innovative credit is compulsory and it's the main way for students to obtain innovative credits to participate in all kinds of subject competitions. Divide different credit rating for participating in competition preparation, completing works, taking part in the competition and winning different awards. The innovation credit system enhances students' initiative and enthusiasm to participate in the competition in our college, providing the internal driving force for the healthy and continuous development of subject competition. From the development of recent years, students' participation scope has expanded year by year, and the type of competition is also increasing, which currently includes National Mechanical Innovation Design Competition, Challenge Cup, National 3D Modeling Contest, National Engineering Robot, Underwater Robot Competition. Currently, the number of students participating in competitions every year has reached 200. It enriches students' extracurricular learning content, and creates a good science and technology culture atmosphere in campus, effectively promoting the improvement of students' innovative and practical ability and comprehensive quality. 


\section{B. University-School Supervise Together to Promote the Development of Subject Competition}

Treat Academic Affairs Office as the core functional department of colleges and universities, which is responsible for the comprehensive management and overall arrangement of various subject competitions. It should extensively carry out school-level subject competitions, and encourage students to participate in subject competitions at provincial level or above. Adopt the principle of selecting college students at college level, university level, provincial level and national level. Select excellent contestants through college subject competitions which are regularly held every year, and let them participate in competitions at provincial level or above after gathered-training. And actively encourage students to participate in international, national, provincial competitions.

According to the characteristics of mechanical specialty and different interests of students, as well as the different focus of various competitions in the cultivation of students' quality, our college form different groups in advance to train different types of subject competition preparation team, so that various subject competitions which are suitable for mechanical specialty can develop and select contestants in our college orderly. Let the subject competition really connect in class and after class effectively. Improve the students' innovative and practical ability while enriching the campus culture.

\section{Open Special Courses for Subject Competition Training to Prepare for the Project}

In order to improve the quality of various subject competitions, our college has hired teachers who are good at different directions to conduct targeted teaching for interest groups. Teaching time is generally more than one year before the corresponding competition, so that the problems found in the middle of project implementation can be resolved and improved in advance. The teaching content is directly related to the content of competitions, so as to prepare for the competition. The competition content will be taught in the second classroom to prepare for the competition, stepping up enforcement of project and improving its quality.

\section{Build Subject Competition Website and Information Exchange Platform}

Because of various types of subject competition projects, large number of participating students and cumbersome process management, the workload is large if we only conduct the management with general computer files. Therefore, Suzhou University of Science and Technology has developed the website of "Subject Competition Information Interaction Platform". University can regularly publish a variety of competition information for students through the platform. And students will be able to register online, learn about the latest competition announcements, inquire about innovative credits, report on project progress, review project progress, and so on. The "Subject Competition Information Interaction Platform" greatly facilitates participating students and teaching affair administration, and speeds up the exchange of information, making the subject competition be carried out more smoothly.

\section{The Operating Procedures of SubJect Competition SYSTEM}

Subject competition system running clearly and smoothly is an important guarantee for the smooth and efficient subject competition. After the practice and exploration of the collegelevel subject competition, Suzhou University of Science and Technology has gradually formed standardized and disciplinary competition system operating procedures.

\section{A. Publicity before Competition}

At the beginning of each natural year, the Academic Affairs Office organizes each college to make a plan for competitions they are going to participate in this year, and makes overall arrangements about the competition time of all the subject competitions based on the characteristics of subject and publishes it on the "Subject Competition Information Interaction Platform". Therefore, students can rationally arrange the time and participate in the competition based on their interest, which helps to improve the learning interest and initiative of students. Carry out extensive publicity before subject competition, accept groups which receive training in advance to take part in the competition, and attract next set of students to learn about relevant subject competition in advance, so that they can participate in the competition activities in advance.

\section{B. Strict Supervision During Competition}

The participation process of the subject competition is also a process of comprehensive training of students' body and mind. The students' learning ability, perseverance and will, as well as the good teamwork spirit, all can be trained and improved through the competition. Therefore, the process management of competition is particularly important in the whole competition. It is an important link in which students can get practical training, improvement, perception, and stimulate their innovative thinking.

In the competition process, always firmly grasp students' points of interest and guide them. Change the extensive management model, standardize the process management, and coordinate relevant departments to carry out the process management of competition in an organized and planned way. Participating students are required to conduct a summary of their work on "Subject Competition Information Interaction Platform" every two weeks, and a full-time teacher will review them. At the same time, a three-step management model of "lecture-tutor-strengthen" is adopted: conduct intensive training of some special competition for students to expand their mind, so that they can achieve good results in high-level subject competitions. Train and improve students' innovative and practical ability in the process of competition.

\section{Summary after Competition}

After subject competitions, person in charge of subject competition need to conduct an overall summary on the whole process of the competition: competition plan, publicity materials, registration statistics, competition questions and judgment standard, competition works display, winners' feelings and experiences, experience and shortcomings of the 
competition, and report the relevant information to the "Subject Competition Information Interaction Platform", retaining the valuable experience and first-hand information. Regularly held subject competition report-back meeting and student subject competition forum to continuously pass on experience and improve the shortcomings of the competition, which helps to promote the continuous improvement of subject competition.

\section{Perfect Safeguard Mechanism of SubJect COMPETITION SYSTEM}

Scientific and reasonable safeguard mechanism is one of the key factors for the smooth and effective development of the subject competition system. The safeguard mechanism mainly includes: management system safeguard of subject competition system, competition funds safeguard and incentive system safeguard.

\section{A. Management System Safeguard of Subject Competition System}

1) University-college subject competition management system.

In order to further strengthen the organization and management of subject competition and improve the level of subject competition, university-college produces a series of documents to strengthen the organization and management of student subject competition. Competition management institution has formed university-college two-level management model, building a sound management organization from top to bottom. The Academic Affairs Office is mainly responsible for subject competition policy formulation, project approval, fund management, publicity and recognition. Our college is responsible for the organization, management and implementation of various subject competitions related to mechanical specialty. Besides as the organizer of subject competition, our college also undertakes extensive publicity and full mobilization of students to participate in competitions. The Academic Affairs Office takes the development of subject competition and participation of the students as the special assessment indicators for the secondary college teaching evaluation: mobilize the work enthusiasm of secondary colleges through the bonus system for awardwinning students or instructors' college, forming a virtuous circle management system of university overall managing, college implementing and students actively participating.

\section{2) The incentive system for instructors.}

Give subsidies to instructors who conduct lectures and answer questions in competition according to their workload, and make it an important part of performance appraisal. In addition, in teachers' professional title evaluation, set corresponding bonus system for teachers who guide participating students to win awards in subject competition at provincial level or above, and give them the same amount of bonus cash as the winning students get. For publication or invention patent project of which student is the first author and instructor is corresponding author, it's identified as the performance of the instructor in the title assessment. Through various policies and measures, the team of competition instructors has become more and more stable, which creates a high-level quality instructor team for the healthy development of the subject competition.

\section{B. Subject Competition Funds Safeguard}

The Academic Affairs Office will allocate special funds for subject competition activities. For each competition, the college will give the secondary college a certain amount of funds, including funds for pre-competition publicity, registration and organization; materials expense subsidy for material-consumption competitions, and question fee and review fee for question setting, etc. This lays a good foundation for the orderly development of subject competition. For the laboratory facilities, competition venues and other hardware facilities that subject competition requires, the university has configured a number of equipment based on the original basic conditions, providing a hardware foundation for the smooth development of subject competition activities.

\section{Incentive System Safeguard}

Bring subject competition into the talent training program, and give innovative credits to all participating students who enter the next round of competition or win awards. This incentive policy greatly improves the enthusiasm of students to participate and enhance the students' sense of honor. Hold an university subject competition award-giving meeting each school year, invite the school leaders to personally award the certificate of honor and prize to the winning students, and arrange the outstanding winning students to give speeches. Put up posters in campus to promote the activity. For students winning awards above provincial level, the school sets up special funds to award scholarship to them. In addition, the school also actively encourages student community to carry out healthy and beneficial scientific and cultural activities, guides the academic and technological community to develop quality activities. The school is striving to build a diversified community activity platform, so that students can exchange experience, learn from each other and help each other forward. At the same time, it can also play the role of mentoring and carry out subject competition activity in a deep-going way.

\section{InNOVAtive AND PRACTICAl ABILITY CULTIVATION EFFECT OF SUbJECT COMPETITION SYSTEM}

Through the survey of 32 students who participated in the competition, it is found that the basic mechanical knowledge of these students is very solid, and they have clear project design ideas and strong practical ability. At the same time, they have strong team consciousness, and good coordination and cooperation ability, interpersonal communication skills and organizational coordination ability.

Over the past three years, through participation in subject competition, students of mechanical specialty in our college have won 18 first-class prizes, 46 second-class prizes and 26 third-class prizes in all kinds of national subject competitions. They have won more than 80 prizes in provincial and municipal competitions, and published 12 scientific and technological papers of which the first author is students. The teachers and students have also applied for and authorized 26 invention patents and 63 utility model patents. From the above 
results, the subject competition system not only cultivates students' ability to learn and apply professional knowledge, but also fosters students' innovative and practical ability and arouses their initiative and enthusiasm of learning. It is beneficial to the training of students' individualization, and improvement of their ability of self-learning and scientific research and innovation practice; it helps students develop team spirit, enhance teamwork and improve the ability to organize and awareness to actively participate in competition; it allows students to improve practical and innovative ability. Subject competition system built based on subject competition of college students is of great significance to cultivating innovative talents and continuously improving teaching quality through formation of innovative cultural atmosphere in campus

\section{CONCLUSION}

Nowadays, the cultivation of innovative consciousness and practical ability is the goal and development direction of practical teaching in colleges and universities. And innovative practical education based on subject competition provides a brand-new platform for innovation consciousness and practical ability education. Through the research on the actual situation of innovation practice education and the reform of innovation practice teaching in our university which use subject competition as carrier, this paper puts forward some new innovative practice teaching methods with the subject competition as carrier, and they have achieved good teaching effect.

\section{REFERENCES}

[1] Fu Xiong, Chen Chunling. Research on the Cultivation of College Students' Innovative and Practical Ability with the Subject Competition as the Carrier [J]. Computer Education, 2011 (6): 29-31.

[2] Chen Lancheng, Bao Hong. Experimental Skills Competition System for Students of Universities of Science and Technology[J]. Laboratory Research and Exploration, 2009,28 (6): 267-270.

[3] Pi Dechang, Wu Qingxian. International Collegiate Programming Contest and Innovative Talents Training [J] .Journal of Electrical \& Electronic Education, 2008 (6): 44-45.

[4] Yang Wei. Cultivation of College Students' Competitive Competence Based on Science-Technology and Learning Competitions[J]. ScienceTechnology and Management, 2010,12 (3): 120-123.

[5] Yang Yitao. Methods of Cultivating Talents Through Combination of College Students Competition and Undergraduate Teaching[J]. Nanchang College Journal, 2010 (5): 77-79.

[6] Bai Yongguo. Research and Practice on Subject Competition System of "Three Levels and Three Directions" for College Students [J]. Journal of Jilin Institute of Chemical Technology, 2012,29 (10): 97-99.

[7] Li Baoling, Gao Zhongyong, Liu Xuhong. Effects of Innovative Design Competition on the Cultivation of Students' Innovative and Practical Ability [J]. Journal of Hezhou University, 2012,28 (2): 99-100. 